\title{
Lack of CD151/integrin $\alpha 3 \beta 1$ complex is predictive of poor outcome in node-negative lobular breast carcinoma: opposing roles of CD151 in invasive lobular and ductal breast
}

\section{cancers}

Hanna M Romanska*,1, Piotr Potemski ${ }^{2}$, Magdalena Krakowska², Magdalena Mieszkowska ${ }^{3}$, Shalini Chaudhri ${ }^{4}$, Radzisław Kordek ${ }^{1}$, Robert Kubiak ${ }^{1}$, Valerie Speirs ${ }^{5}$, Andrew M Hanby ${ }^{5}$, Rafał Sadej ${ }^{*, 3}$ and Fedor Berditchevski ${ }^{6}$ ${ }^{1}$ Department of Pathology, Medical University of Łódź, ul. Pomorska 251, 92-213 Łódź, Poland; ${ }^{2}$ Department of Chemotherapy, Medical University of Łódź and M. Kopernik Memorial Hospital, ul. Paderewskiego 4, 93-509 Łódź, Poland; ${ }^{3}$ Department of Molecular Enzymology, Intercollegiate Faculty of Biotechnology, Medical University of Gdańsk, ul. Dębinki 1, 80-210 Gdansk, Poland; ${ }^{4}$ Department of Cellular Pathology, University of Birmingham, Birmingham, UK; ${ }^{5}$ Leeds Institute of Cancer and Pathology, University of Leeds, Leeds LS9 7TF, UK and ' ${ }^{6}$ School of Cancer Sciences of the University of Birmingham, Birmingham B15 2TT, UK

Background: The proposed involvement of CD151 in breast cancer (BCa) progression is based on findings from studies in invasive ductal carcinoma (IDC). The IDC and invasive lobular carcinoma (ILC) represent distinct disease entities. Here we evaluated clinical significance of CD151 alone and in association with integrin $\alpha 3 \beta 1$ in patients with ILC in context of the data of our recent IDC study.

Methods: Expression of CD151 and/or integrin $\alpha 3 \beta 1$ was evaluated in ILC samples $(N=117)$ using immunohistochemistry. The findings were analysed in relation to our results from an IDC cohort $(N=182)$ demonstrating a prognostic value of an expression of CD151/integrin $\alpha 3 \beta 1$ complex in patients with HER2-negative tumours.

Results: Unlike in the IDCs, neither CD151 nor CD151/ $\alpha 3 \beta 1$ complex showed any correlation with any of the ILC characteristics. Lack of both CD151 and $\alpha 3 \beta 1$ was significantly correlated with poor survival $(P=0.034)$ in lymph node-negative ILC N $(-)$ cases. The $\mathrm{CD} 151^{-} / \alpha 3 \beta 1^{-}$patients had 3.12-fold higher risk of death from BCa in comparison with the rest of the ILC N(-) patients.

Conclusions: Biological role of CD151/ $\alpha 3 \beta 1$ varies between ILC and IDC. Assessment of CD151/ $\alpha 3 \beta 1$ might help to identify ILC $\mathrm{N}(-)$ patients with increased risk of distant metastases.

The tetraspanin protein CD151 (Tspan24) has recently emerged as a new candidate indicator of tumour cell invasiveness (Boucheix and Rubinstein, 2001; Hemler, 2005; Zoller, 2009). Elevated expression of CD151 protein and its involvement in tumour progression have been observed in various human malignancies (Romanska and Berditchevski, 2011). In breast cancer (BCa), in particular, high expression of tetraspanin CD151 was shown to correlate with axillary lymph node involvement and patient poor overall survival (Sadej et al, 2009; Kwon et al, 2012; Novitskaya et al, 2014). The role of CD151 in tumour invasive and metastatic progression is thought to be relying on its ability to form complexes with laminin-binding integrin receptors (i.e., $\alpha 6 \beta 1$, $\alpha 3 \beta 1, \alpha 6 \beta 4$ ) (Sadej et al, 2014) and its involvement in the regulation of cell-cell and cell-matrix interactions (Johnson et al, 2009). 
The underlying signalling pathways are likely to depend on adhesion-dependent and coordinated activation of small Rho and Ras GTPases, c-Akt and p38 (Novitskaya et al, 2014). It was also proposed that the CD151/ $\alpha 3 \beta 1$ complex is directly linked to cadherin and catenin, thus regulating E-cadherin-mediated cell-cell adhesion (Chattopadhyay et al, 2003). A suppressive role of the CD151/ $\alpha 3 \beta 1$ complex, recently demonstrated in ovarian cancer, has been linked to stabilisation of integrin $\alpha 3 \beta 1$ - and E-cadherin-mediated cell-cell contacts (Baldwin et al, 2014). In addition to its role in regulation of adhesion-dependent outside-in signalling pathways, CD151 might contribute to mammary tumourigenesis via ErbB2/HER2 (Deng et al, 2012; Novitskaya et al, 2014). Interestingly, clinical analyses of BCa patients showed that the elevated expression of CD151 correlated with poor overall survival in patients only with HER2-negative (luminal A and quintuple-negative) tumours (Kwon et al, 2012). Moreover, an impact of CD $151 / \alpha 3 \beta 1$ on invasive ductal carcinoma (IDC) patient survival was shown to be inversely correlated with the level of HER2 expression (Novitskaya et al, 2014).

Existing knowledge of CD151 involvement in mammary tumourigenesis is almost exclusively based on clinical and in vitro studies of the IDC. However, it is becoming increasingly apparent that CD151 might have diverse, even opposing roles, in different biological contexts and its clinical significance should be investigated in relation to the phenotypical and histological variants of the tumour (Voss et al, 2011).

Invasive lobular carcinoma (ILC) accounts for $\sim 10 \%$ to $15 \%$ of newly diagnosed breast carcinomas. Classical ILCs are characterised by an outgrowth of small, uniform discohesive neoplastic cells that invade the stroma in a single-file pattern (Sikora et al, 2014). The majority of ILC tumours are of low histological grade and preferentially display a luminal A phenotype $(\mathrm{ER}+/ \mathrm{PR}+1$ HER2 - ) (Weigelt et al, 2010). Classical ILCs lack E-cadherin expression that is considered a defining feature of this BCa type (Sikora et al, 2014). Recent studies demonstrated that ILCs differ from grade- and molecular subtype-matched IDCs in the transcriptomic profiles related to cell adhesion, cell-cell signalling and metastatic pattern, indicating that IDCs and ILCs represent distinct disease entities (Weigelt et al, 2010; Sikora et al, 2014).

Because of the relatively low incidence of ILC as well as the paucity of available research models (Sikora et al, 2014), the mechanisms underlying its pathophysiology are poorly understood. It is likely that the role of CD151 in progression of E-cadherin-inactivated ILCs, and hence its impact on patient outcome, differs from those documented in the more common IDCs. To date, CD151 expression has been studied only in a few ILC cases, a small part $(2.9 \% ; 25$ out of 886$)$ of a large cohort analysed according to the phenotypical and not the histological subtypes (Kwon et al, 2012). More information is available regarding expression of integrins in ILC. Most reports are in agreement that malignant ILC phenotype is associated with decrease of expression of a range of integrin subunits. However, independently, the integrins seem to be of limited clinical value as no correlation between their expression, histological grade, nodal involvement, proliferative activity or, above all, the overall survival has ever been found (Gui et al, 1995; Lanzafame et al, 1996; Gonzalez et al, 1999; Gonzalez-Angulo et al, 2006).

The $\alpha 3 \beta 1$ integrin forms a stoichiometric complex with the tetraspanin CD151 and the interaction with CD151 is functionally important in $\alpha 3$ integrin-dependent matrix remodelling and cell spreading (Kazarov et al, 2002). The aim of our study was to assess clinical significance of CD151 alone and in association with integrin $\alpha 3 \beta 1$ in a group of patients with ILC. The findings were analysed in context of our recent IDC study demonstrating a prognostic value of an expression of integrin CD151/ $\alpha 3 \beta 1$ complex in patients with HER2-negative tumours (Novitskaya et al, 2014).

\section{MATERIALS AND METHODS}

Patient selection and samples. The study included radical surgery specimens of primary ILC from 117 patients treated between 2000 and 2008 at three sites: (1) the Oncology Department of Copernicus Memorial Hospital in Łódź, Poland, (2) the UHB NHSFT, Birmingham, UK and (3) the Leeds Teaching Hospitals NHS Trust, Leeds, UK. All samples were obtained according to the local ethical regulations (project ethics licence: RNN/174/11/KE). The characteristics of the study population are summarised in Table 1. Follow-up period was defined as the time from surgery to the last observation for censored cases or death for complete observations.

Immunohistochemistry. Serial $5 \mu \mathrm{m}$ paraffin sections of formalin-fixed blocks were processed for immunohistochemistry for CD151 (mouse anti-human; 1:100; Novocastra, Newcastle upon Tyne, UK) and $\alpha 3 \beta 1$ (INTA3) (goat anti-human; $1: 200$, Santa Cruz, Wembley, UK) using protocols described previously (Novitskaya et al, 2014). Immunostaining for E-cadherin (mouse anti-human, 1:50; Novocastra) was used to confirm the initial pathological diagnosis of ILC (E-cadherin-positive samples were excluded from the study). As a negative control for the immunostaining, primary antibodies were replaced by nonimmune sera.

Scoring of immunostaining for CD151 was based on Hofmann's method for membranous reactivity of ErbB2 (Hofmann et al, 2008) and modified as follows: (1) 0/negative: no reactivity or only partially membranous reactivity in $\leqslant 10 \%$ of tumour cells; (2) $1+1$ negative: faint membranous or partially membranous in $\geqslant 10 \%$ of tumour cells; (3) $2+/$ positive: weak to moderate complete membranous in $\geqslant 10 \%$ of tumour cells; and (4) $3+/$ positive: strong complete membranous in $\geqslant 10 \%$ of the tumour cells. Immunoreactivity for $\alpha 3 \beta 1$ was scored as follows: (1) 0/negative:

\begin{tabular}{|c|c|c|}
\hline Feature & ILC & IDC \\
\hline Number of patients & 117 & 182 \\
\hline \multicolumn{3}{|l|}{ Age (years) } \\
\hline$<50$ & 21 & 56 \\
\hline$\geqslant 50$ & 96 & 127 \\
\hline \multicolumn{3}{|l|}{ Disease stage $^{a}$} \\
\hline 1 & 34 & 44 \\
\hline II & 60 & 93 \\
\hline III & 13 & 45 \\
\hline \multicolumn{3}{|l|}{ T status $^{b}$} \\
\hline T1 & 52 & 61 \\
\hline $\mathrm{T} 2$ & 48 & 112 \\
\hline T3 & 15 & 1 \\
\hline T4 & 1 & 8 \\
\hline \multicolumn{3}{|l|}{ Grade $^{c}$} \\
\hline 1 & 21 & 105 \\
\hline $2-3$ & 94 & 77 \\
\hline \multicolumn{3}{|l|}{ Nodal status ${ }^{d}$} \\
\hline Negative & 64 & 92 \\
\hline Positive & 44 & 90 \\
\hline \multicolumn{3}{|c|}{ Steroid receptor status ${ }^{\mathrm{e}}$} \\
\hline Negative & 11 & 79 \\
\hline Positive & 102 & 103 \\
\hline \multicolumn{3}{|l|}{ HER2 status ${ }^{f}$} \\
\hline Negative & 102 & 151 \\
\hline Positive & 4 & 31 \\
\hline \multicolumn{3}{|c|}{$\begin{array}{l}\text { Abbreviations: IDC }=\text { invasive ductal carcinoma; ILC }=\text { invasive lobular carcinoma. In the ILC } \\
\text { group, data are available for }{ }^{\mathrm{a}} 107 \text { patients, }{ }^{b} 116 \text { patients, }{ }^{c} 115 \text { patients, }{ }^{d} 108 \text { patients, }{ }^{\mathrm{e}} 113 \\
\text { patients and }{ }^{f} 106 \text { patients. }\end{array}$} \\
\hline
\end{tabular}


no reactivity; (2) $1+$ /positive: faint membranous and/or cytoplasmic staining in $\geqslant 10 \%$ of tumour cells; (3) $2+$ /positive: weak to moderate membranous and/or cytoplasmic staining in $\geqslant 10 \%$ of tumour cells; and (4) $3+$ /positive: strong membranous and/or cytoplasmic staining in $\geqslant 10 \%$ of the tumour cells. Immunohistochemical staining was evaluated and scored independently by two observers (HMR and R Kordek or HMR and SC). The agreement on staining intensity was $>90 \%$. Where there was disagreement, intensity was determined by consensus. Dichotomisation of the final scores into: (1) 'negative' and (2) 'positive' for CD151/0-2; INTA3/0 and CD151/3 and INTA3/1-3, respectively, was guided by intensity of immunostaining in positive controls recommended by the manufacturer.

Statistical analysis. Overall survival was calculated from the date of surgery to the date of death or the last follow-up, as recommended by the Kaplan-Meier method. Differences in survival distributions were compared using log-rank test. Data for patients who died from other causes than BCa were censored at the time of death. Univariate analysis of overall survival was performed using the Cox proportional hazards regression model. Parameters showing a significant correlation $(P<0.05)$ were included in the multivariate logistic regression analysis. Pearson's $\chi^{2}$ test or Fisher's exact test were used to assess the associations between expression of CD151 and $\alpha 3 \beta 1$ alone and their coexpression and clinicopathological variables. The results were considered statistically significant when two-sided $P$-value was $<0.05$. The analyses were performed using the Statistica 9.1 and Statistica 10 (StatSoft Inc., Tulsa, OK, USA) softwares.

Data on cancer recurrence were available in only four cases that precluded the DFS analysis.

\section{RESULTS}

An impact of CD151/ $\alpha 3 \beta 1$ on tumour biology differs between ILC and IDC. In normal gland, both CD151 and $\alpha 3 \beta 1$ showed moderate to strong, predominantly membranous immunoreactivity, confined to the basal and lateral surfaces of the myoepithelial cells, with no or very weak staining in luminal epithelial cells (Figure 1A). Similarly, in ILCs, CD151 and $\alpha 3 \beta 1$ were localised mainly to the membrane of tumour cells and there was a significant correlation $(P=0.012)$ between levels of their expression (Table 2A). We observed four distinct patterns of immunoreactivity for CD151/ $33 \beta 1$ : (1) $\mathrm{CD} 151+/ \alpha 3 \beta 1+$ in 55 out of $117(23.94 \%)$ cases; (2) CD151 + / $\alpha 3 \mathrm{~b} 1-$ in 28 out of 117 (23.94\%) cases; (3) CD151 - / $\alpha 3 \beta 1-$ in 20 out of $117(17.09 \%)$ cases and (4) CD151-/ $\alpha 3 \beta 1+$ in 14 out of $117(11.96 \%)$ cases (Figure 1B-E). Interestingly, the level of CD151 expression (but not expression of $\alpha 3 \beta 1$ ) on cancer cells was similar to that observed on endothelial cells of intratumoural vessels (Figure 2).

There was no significant correlation between the level of $\alpha 3 \beta 1$ expression and any of tumour characteristics (Table 2A). On the other hand, expression of CD151 assessed alone was inversely associated with tumour size $(P=0.047)$ and stage $(P=0.019)$, thus indicating that CD151 might have an ability to suppress proliferation of cells and progression of disease. Interestingly, positivity for both $\mathrm{CD} 151$ and $\alpha 3 \beta 1(\mathrm{CD} 151+/ \alpha 3 \beta 1+)$ was significantly associated only with grade $(P=0.019)$. These results suggest that phenotypic dedifferentiation and adopting of anaplastic features by epithelial cells in ILC are associated with CD151 acting in a complex with $\alpha 3 \beta 1$.

We have previously reported that in IDC, in contrast to ILC, CD151 expression showed a positive association with stage $(P=0.030)$ and inverse with tumour grade $(P=0.041)$. We have also demonstrated that, when assessed in combination, positivity for CD151 and/or $\alpha 3 \beta 1$ correlated closer than CD151 alone with
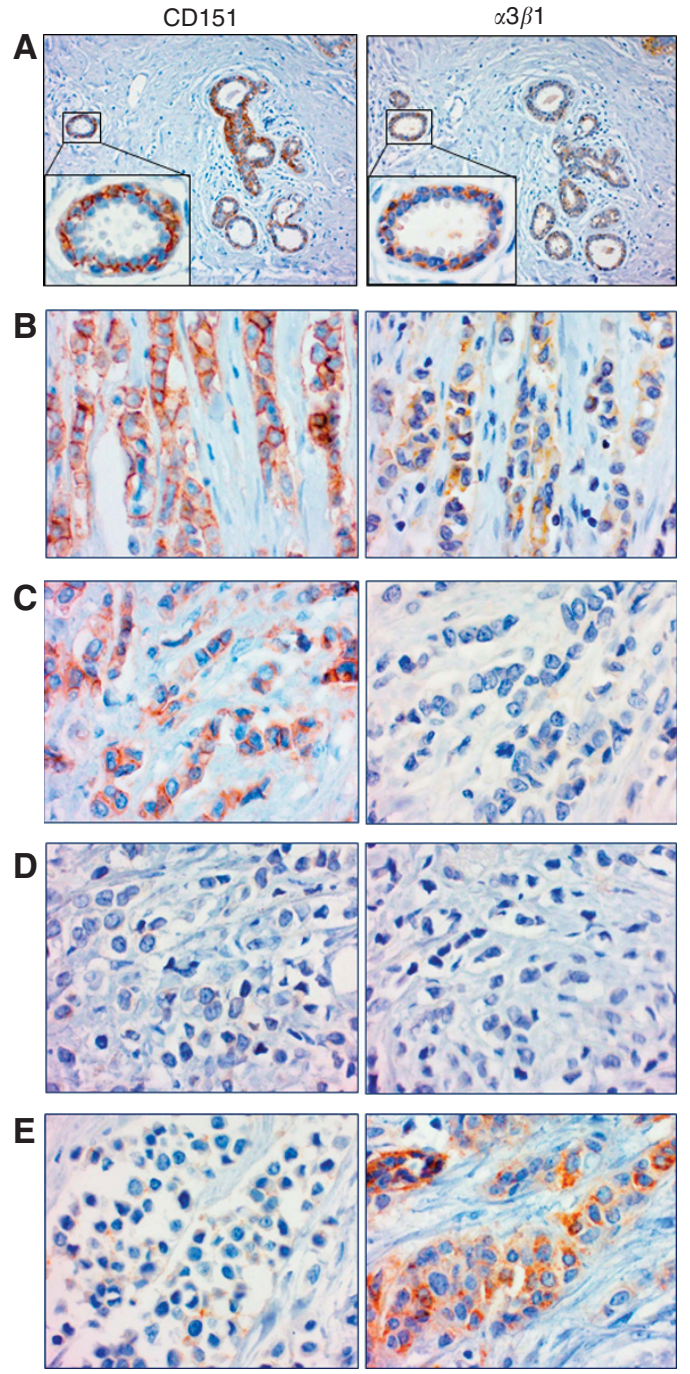

Figure 1. Expression of CD151 and $\alpha 3 \beta 1$ in (A) normal gland ( $\times 100$; insets $\times 400)$. Both CD151 and $\alpha 3 \beta 1$ show moderate to strong, predominantly membranous immunoreactivity, confined to the basal and lateral surfaces of the myoepithelial cells, with no or very weak staining in luminal epithelial cells. (B) The ILC cells of similar areas of the tumour display various levels of CD151/ $\alpha 3 \beta 1$ immunoreactivity representing four predominant phenotypes: (B) CD151 + / $23 \beta 1+$ (55 out of $117 ; 49.01 \%)$; (C) CD151+/ $\alpha 3 \beta 1-(28$ out of $117 ; 23.94 \%$ ) (D) CD151 $/ / \alpha 3 \beta 1-(20$ out of $117 ; 17.09 \%)$ and (E) CD151 $-/ \alpha 3 \beta 1+$ (14 out of $117 ; 11.96 \%$ ).

stage of disease $(P<0.001$ vs $P=0.03$ for $\mathrm{CD} 151 / \alpha 3 \beta 1$ vs CD151, respectively) (Novitskaya et al, 2014). Here we have expanded our previous analyses and evaluated coexpression of CD151 and $\alpha 3 \beta 1$ in the context of histopathological and clinical characteristics of the IDC cohort. The results showed that in contrast to ILCs, combined positivity for both CD151 and $\alpha 3 \beta 1$ showed no correlation with any of the clinicopathological features in IDCs (Table 2B). Taken together, these results suggest that the involvement of CD151 and its principal transmembrane partner, the integrin $\alpha 3 \beta 1$, in tumour development and progression is likely to differ between histological subtypes of $\mathrm{BCa}$.

In ILC, in contrast to IDC, neither CD151 nor $\alpha 3 \beta 1$ hold prognostic value. Neither CD151 nor $\alpha 3 \beta 1$ analysed alone were of any prognostic value in ILCs (Table $3 \mathrm{~A}$ ). In contrast, in IDC, as shown previously, CD151-positive patients had 1.88-fold higher risk of death from $\mathrm{BCa}$ in comparison with $\mathrm{CD} 151$-negative 
Table 2. Association between CD151 and/ $\alpha 3 \beta 1$ expression and clinicopathological features

\begin{tabular}{|c|c|c|c|}
\hline \multirow[b]{3}{*}{ Feature } & \multicolumn{3}{|c|}{$P$-value } \\
\hline & \multicolumn{3}{|c|}{ ILC } \\
\hline & $\alpha 3 \beta 1$ (high: $n=69$ ) & CD151 (high: $n=83$ ) & CD151/ $\alpha 3 \beta 1$ (high: $n=55$ ) \\
\hline$\alpha 3$ & & 0.012 & \\
\hline CD151 & 0.012 & & \\
\hline Size & 0.574 & 0.047 & 0.381 \\
\hline Nodes & 0.464 & 0.277 & 0.101 \\
\hline Stage & 0.656 & 0.019 & 0.387 \\
\hline Grade & 0.093 & 0.343 & 0.019 \\
\hline ErbB2 & 0.092 & 0.881 & 0.249 \\
\hline$E R / P R$ & 0.694 & 0.471 & 0.425 \\
\hline \multicolumn{4}{|l|}{ (B) } \\
\hline \multirow[b]{3}{*}{ Feature } & \multicolumn{3}{|c|}{$P$-value } \\
\hline & \multicolumn{3}{|c|}{ IDC } \\
\hline & $\alpha 3 \beta 1$ (high: $n=32$ ) & CD151 (high: $n=87$ ) & CD151/ $\alpha 3 \beta 1$ (high: $n=26$ ) \\
\hline$\alpha 3 \beta 1$ & & $<0.001$ & \\
\hline CD151 & $<0.001$ & & \\
\hline Size & 0.599 & 0.497 & 0.499 \\
\hline Nodes & 0.271 & 0.076 & 0.413 \\
\hline Stage & 0.545 & 0.030 & 0.174 \\
\hline Grade & 0.163 & 0.041 & 0.162 \\
\hline ErbB2 & $>0.999$ & 0.015 & 0.995 \\
\hline ER/PR & 0.663 & 0.819 & 0.797 \\
\hline
\end{tabular}

patients. Moreover, a multivariate statistical analysis identified CD151 as an independent marker $(P=0.0172)$ of poor prognosis in IDC (Table 4). In neither ILC nor IDC, coexpression was significantly associated with patient survival. Furthermore, although in the IDC cohort, clinicopathological characteristics commonly recognised as independent prognostic factors (tumour size, lymph node status, stage) were significantly associated with poor survival, none of them held any prognostic value in our ILC study population (Table $3 \mathrm{~A}$ and $\mathrm{B}$ ).

Lack of $\mathrm{CD} 151 / \alpha 3 \beta 1$ expression is associated with poor survival in node-negative ILC. As CD151, acting in partnership with $\alpha 3 \beta 1$, is thought to affect invasive spread of tumour cells, we analysed prognostic values of CD151 and/or $\alpha 3 \beta 1$ in the ILC cohort in relation to the lymph node status. The results presented in Table 5 demonstrate that neither CD151 nor $\alpha 3 \beta 1$ assessed alone or in combination had any significant prognostic value in any of the subgroups. Only a trend towards statistical significance $(P=0.082)$ was seen for CD151 in node-negative patients (ILC $\mathrm{N}(-))$. Furthermore, in the ILC $\mathrm{N}(-)$ subgroup, the data were suggestive that the presence of either CD151 or $\alpha 3 \beta 1$ could be favourable to the prognosis but their coexpression had no additive effect on patient survival. Thus, we next looked at the relationships between CD151 and/or $\alpha 3 \beta 1$ and tumour characteristics in the lymph node-negative subgroup (characteristics of the group are summarised in Table 6A). Table $6 \mathrm{~B}$ demonstrates that, as in the whole group, significant correlations between (1) expression of CD151 and $\alpha 3 \beta 1 \quad(P=0.018) ; \quad(2) \quad C D 151$ and tumour size $(P=0.035)$; and $(3) \mathrm{CD} 151 / \alpha 3 \beta 1$ and grade $(P=0.029)$ were maintained. Univariate analysis in ILC $\mathrm{N}(-)$ cases showed that lack of combined expression of CD151 and $\alpha 3 \beta 1$ was significantly correlated with poor patient survival $(P=0.034)$ and was the only prognostic factor in this group (Table 6C). The CD151/ $\alpha 3 \beta 1-$ negative patients had 3.12-fold higher risk of death from $\mathrm{BCa}$ in comparison with the rest of the patients with no lymph node involvement and the 5-year estimated survival rates were $64 \%$ vs $91 \%$, respectively (Figure 3 ).

\section{DISCUSSION}

An overexpression of CD151/Tspan24 has been repeatedly reported as a negative predictor of overall survival in patients with invasive ductal breast carcinoma (Yang et al, 2008; Sadej et al, 2009; Kwon et al, 2012; Novitskaya et al, 2014) but nothing is known about its clinical significance in invasive lobular BCa. Here we demonstrate that, in contrast to IDC, loss of CD151 expression in complex with that of its principal molecular partner, the integrin $\alpha 3 \beta 1$, is significantly associated with poor survival in patients with lymph node-negative ILC. There have been a few attempts to establish an expression signature of a risk of distant metastasis in primary lymph node-negative IDC (Mirza et al, 2002; Wang et al, 2007; Tutt et al, 2008). To the best of our knowledge, this is the first study providing information on prognostic factors in a subgroup of lymph node-negative ILC patients.

The results of our study provide support for the notion of biological diversity of CD151 in human cancer. Acting alone and/or in complex with laminin-binding integrins, CD151 has been linked with various aspects of carcinogenesis (Palmer et al, 2014; Sadej et al, 2014). Although its pro-migratory and proinvasive functions are well established, it was also reported that in certain cell types the presence of CD151 is associated with suppression of motility. For example, its downregulation induced by hypoxic stress at the primary site in colon cancer was shown to 

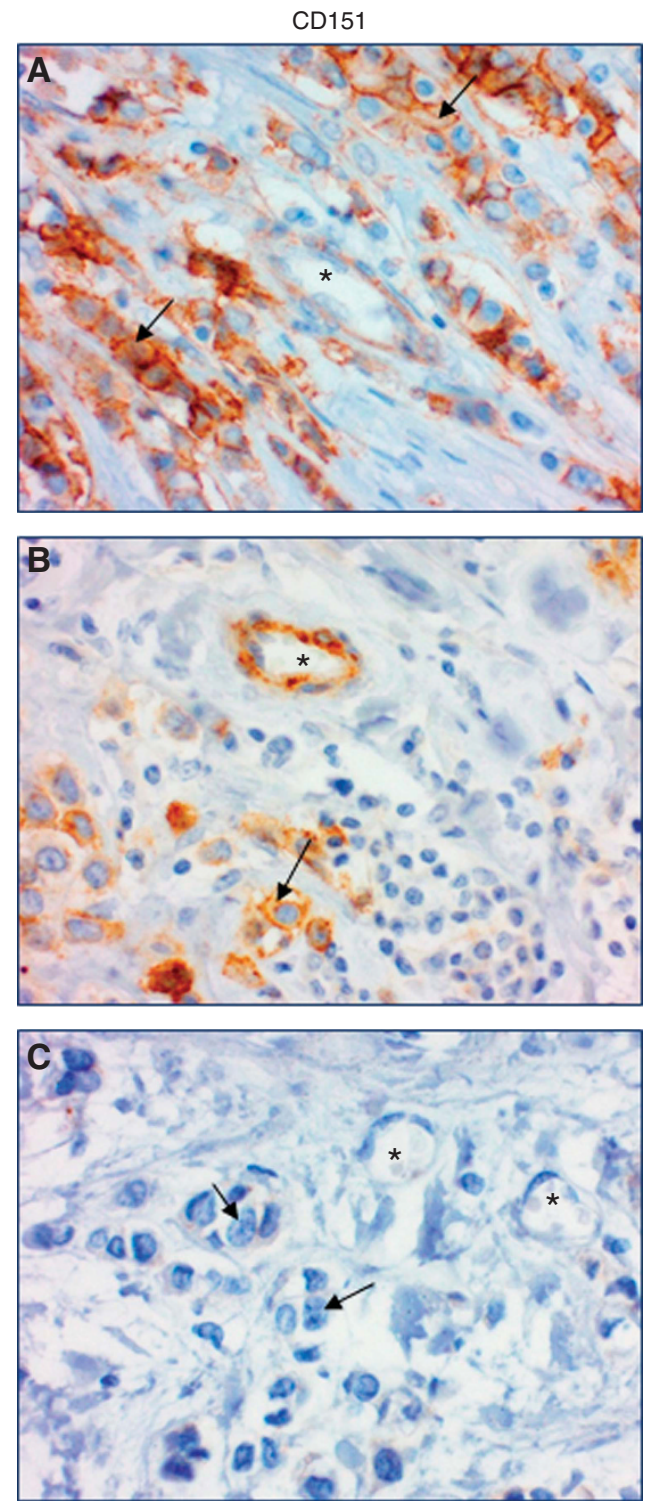

Figure 2. Expression of CD151 in intratumoural vessels $(\times 400)$. Level of expression in endothelial cells of intratumoural vessels (asterisks) is consistent with that in epithelial cells of adjacent tumour (arrows) ( $A$, high; $B$, moderate; $C$, negative).

decrease adhesion of cells to the extracellular matrix and enhance cell motility (Chien et al, 2008). Similarly, both up- and downregulation of integrin $\alpha 3 \beta 1$ expression have been correlated with tumour invasion and poor prognosis (Adachi et al, 1998; Fukushima et al, 1998; Gustafson-Wagner and Stipp, 2013). Furthermore, the CD151/ $\alpha 3 \beta 1$ complex has been recently shown to suppress ovarian tumour growth (Baldwin et al, 2014). Although in our study no prognostic value could be ascribed to either CD151 or $\alpha 3 \beta 1$ assessed alone, their independent suppressor-like functions cannot be excluded. Further mechanistic investigation would be required to evaluate an actual impact of a loss of the CD151/ $\alpha 3 \beta 1$ complex on ILC tumour behaviour.

Increasing evidence suggests that ILCs and IDCs are biologically different. This is reflected in disparities in morphological and phenotypic characteristics, transcriptomic profiles related particularly to cell-cell and cell-matrix interactions (Weigelt et al, 2010), as well as responsiveness to neoadjuvant therapy (Korkola et al, 2003). As demonstrated by several genomic studies, the only consistent finding characterising ILC tumours is inactivation of CDH1 (E-cadherin, cadherin-1) (Bertucci et al, 2008; Weigelt et al,
Table 3. Univariate analysis of prognostic factors

\begin{tabular}{|c|c|c|c|}
\hline \multicolumn{4}{|l|}{ (A) } \\
\hline \multirow[t]{2}{*}{ Factor } & $\mathrm{HR}$ & $95 \% \mathrm{Cl}$ & $P$-value \\
\hline & \multicolumn{3}{|c|}{ ILC } \\
\hline$\alpha 3 \beta 1$ & 0.80 & $0.39-1.61$ & 0.750 \\
\hline CD151 & 0.56 & $0.28-1.14$ & 0.109 \\
\hline CD151/ $/ 3 \beta 1$ & 0.72 & $0.35-1.49$ & 0.380 \\
\hline (T1 vs T2-4) & 1.78 & $0.84-3.78$ & 0.165 \\
\hline Nodal status & 1.61 & $0.78-3.31$ & 0.195 \\
\hline Stage (I vs || vs III) & 2.08 & $0.85-5.11$ & 0.111 \\
\hline$E R / P R$ & 0.46 & $0.17-1.19$ & 0.110 \\
\hline HER2 & $N A^{a}$ & $N A^{a}$ & $N A^{a}$ \\
\hline Grade (G1-2 vs G3) & 1.46 & $0.55-3.87$ & 0.441 \\
\hline \multicolumn{4}{|l|}{ (B) } \\
\hline & \multicolumn{3}{|c|}{ IDC } \\
\hline$\alpha 3 \beta 1$ & 1.10 & $0.60-2.03$ & 0.750 \\
\hline CD151 & 1.88 & $1.15-3.08$ & 0.012 \\
\hline CD151/ $33 \beta 1$ & 0.98 & $0.48-1.98$ & 0.952 \\
\hline (T1 vs T2-4) & 1.77 & $1.30-2.40$ & $<0.001$ \\
\hline Nodal status & 3.01 & $1.78-5.10$ & $<0.001$ \\
\hline Stage (I vs || vs III) & 1.81 & $1.27-2.57$ & $<0.001$ \\
\hline$E R / P R$ & 0.53 & $0.33-0.87$ & 0.011 \\
\hline HER2 & 2.07 & $1.18-3.64$ & 0.012 \\
\hline Grade (G1-2 vs G3) & 1.24 & $0.76-2.01$ & 0.383 \\
\hline \multicolumn{4}{|c|}{$\begin{array}{l}\text { Abbreviations: } \mathrm{Cl}=\text { confidence interval; } E R / P R=\text { oestrogen receptor/progesterone recep- } \\
\text { tor; } \mathrm{HR}=\text { hazards ratio; IDC = invasive ductal carcinoma; ILC= invasive lobular carcinoma; } \\
\mathrm{NA}=\text { not analysed. } \\
\text { a Only } 4 \text { were HER2 positive. The bold values are statistically significant. }\end{array}$} \\
\hline
\end{tabular}

Table 4. Multivariate analysis of prognostic factors

\begin{tabular}{|l|c|c|c|}
\cline { 2 - 4 } \multicolumn{2}{l|}{} & \multicolumn{3}{c|}{ IDC } \\
\hline Factor & HR & $\mathbf{9 5 \% ~ C l}$ & $\boldsymbol{P}$ value \\
\hline CD151 & 1.92 & $1.12-3.31$ & $\mathbf{0 . 0 1 7 2}$ \\
\hline (T1 vs T2-4) & 1.98 & $0.94-4.15$ & 0.0711 \\
\hline Nodal status & 4.11 & $2.04-8.29$ & $<0.0001$ \\
\hline Stage (I vs II vs III) & 0.68 & $0.38-1.23$ & 0.2063 \\
\hline ER/PR & 0.53 & $0.32-0.91$ & 0.0198 \\
\hline HER2 & 1.20 & $0.71-2.04$ & 0.1927 \\
\hline AbE
\end{tabular}

Abbreviations: $\mathrm{Cl}=$ confidence interval; $E R / P R=$ oestrogen receptor/progesterone receptor; $\mathrm{HR}=$ hazards ratio; IDC = invasive ductal carcinoma. The bold values are statistically significant.

Table 5. Univariate analysis of prognostic value of CD151 and/or $\alpha 3 \beta 1$ in relation to lymph node status

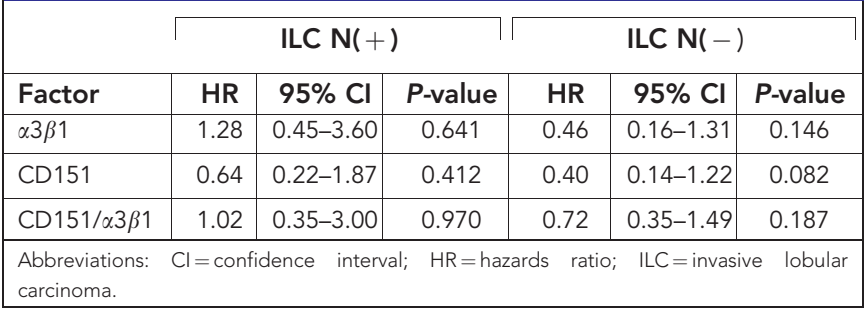

2008, 2010; Sikora et al, 2013) and, indeed, lack of E-cadherin expression is considered a hallmark of ILC. Although the role of E-cadherin in tumour onset and progression is still largely unknown, its inactivation alone is clearly not sufficient to induce 
Table 6A. Lymph node-negative subgroup. Patient characteristics

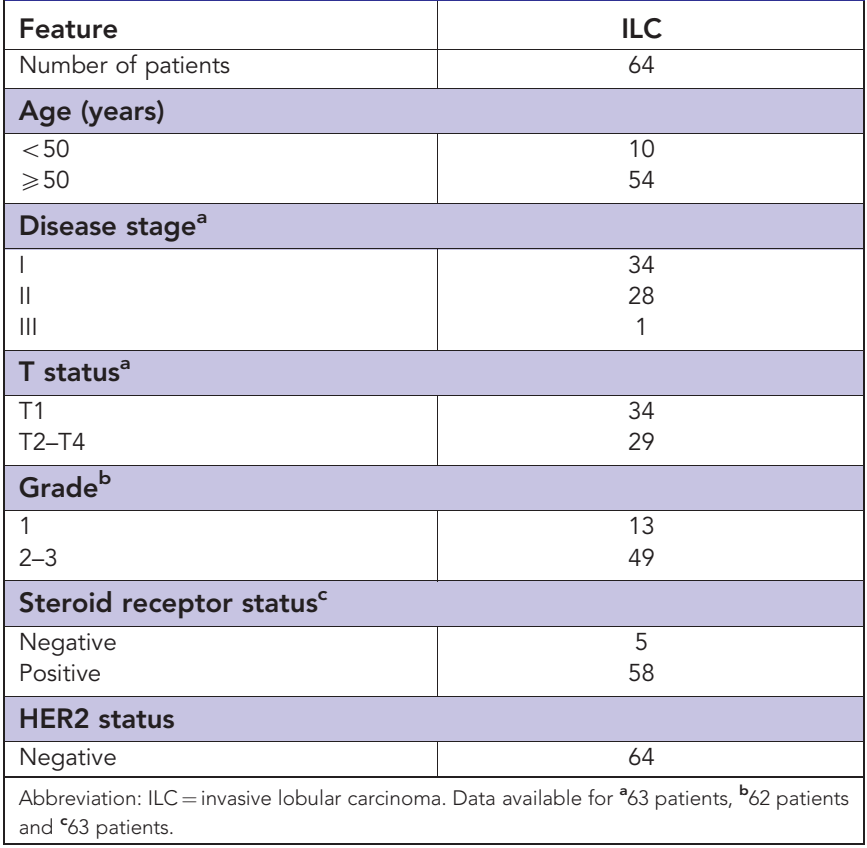

6B. Association of CD151 and/or $\alpha 3 \beta 1$ and tumour characteristics

\begin{tabular}{|c|c|c|c|}
\hline & $\begin{array}{c}\alpha 3 \beta 1 \\
\text { (high: } n=38)\end{array}$ & $\begin{array}{c}\text { CD151 } \\
\text { (high: } n=47)\end{array}$ & $\begin{array}{l}\text { CD151/ } \alpha 3 \beta 1 \\
\text { (high: } n=32 \text { ) }\end{array}$ \\
\hline$\alpha 3 \beta 1$ & & 0.018 & \\
\hline CD151 & 0.018 & & \\
\hline Tumour size (T1 vs T2-4) & 0.312 & 0.035 & 0.892 \\
\hline Grade & 0.079 & 0.342 & 0.029 \\
\hline HER2 & $N A^{a}$ & $N A^{a}$ & $N A^{a}$ \\
\hline ER & 0.377 & 0.999 & 0.192 \\
\hline PR & $N A^{b}$ & $N A^{b}$ & $N A^{b}$ \\
\hline \multicolumn{4}{|c|}{ 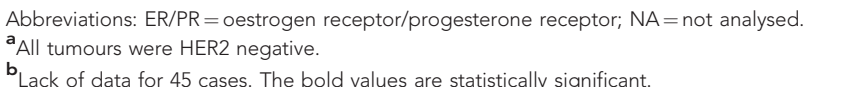 } \\
\hline
\end{tabular}

6C. Univariate analysis of prognostic factors

\begin{tabular}{|c|c|c|c|}
\hline \multirow[b]{2}{*}{ Factor } & \multicolumn{3}{|c|}{$\operatorname{ILC} N(-)$} \\
\hline & HR & $95 \% \mathrm{Cl}$ & $P$-value \\
\hline$\alpha 3 \beta 1$ & 0.462 & $0.16-1.31$ & 0.146 \\
\hline CD151 & 0.402 & $0.14-1.22$ & 0.082 \\
\hline CD151/ $\alpha 3 \beta 1$ & 0.724 & $0.35-1.49$ & 0.187 \\
\hline CD151 - / $\alpha 3 \beta 1-$ & 3.125 & $1.09-8.99$ & 0.034 \\
\hline Tumour size (T1 vs T2-4) & 1.780 & $0.61-5.18$ & 0.290 \\
\hline Grade & 1.361 & $0.36-5.14$ & 0.650 \\
\hline ER & 0.372 & $0.08-1.72$ & 0.206 \\
\hline
\end{tabular}

neoplastic growth. It has been shown that combined loss of E-cadherin and p53, but not E-cadherin alone, in murine mammary epithelial cells induces metastatic carcinomas that resemble human ILC (Derksen et al, 2006).

There are several reports suggesting that an association of CD151 with integrin $\alpha 3 \beta 1$ might be important for regulation of E-cadherin-dependent cell-cell interactions. In mouse kidney, the

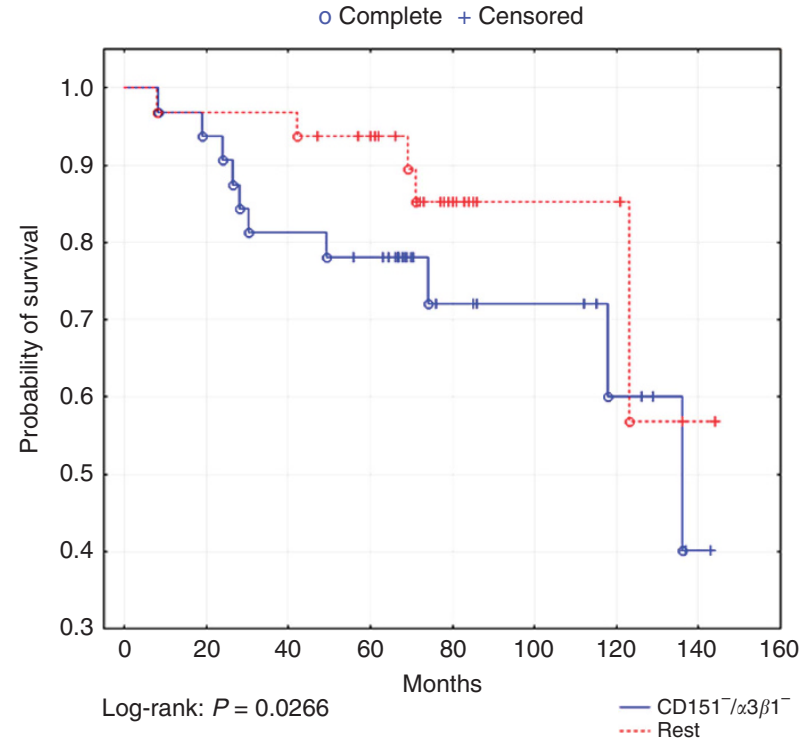

Figure 3. Kaplan-Meier curves of overall survival for patients with invasive lobular breast cancer. Overall survival of patients with tumours negative for both CD151 and $\alpha 3 \beta 1$ in relation to the rest of the cohort.

CD151/integrin $\alpha 3 \beta 1$, acting as both an organiser and a component of a large multimolecular complex containing E-cadherin- $\beta$-catenin, promoted its association with the actin cytoskeleton and cadherinmediated cell-cell adhesion. Deletion of integrin $\alpha 3 \beta 1$ in this system was found to disturb E-cadherin localisation and function (Chattopadhyay et al, 2003). In highly expressing E-cadherin human keratinocytes (HaCat cell line), blocking of CD151 supported cell dispersal (Chometon et al, 2006), whereas CD151 overexpression enhanced carcinoma cell-cell association (Shigeta et al, 2003). Similarly, in A431 epithelial carcinoma cells, near total silencing of CD151 destabilised E-cadherin-dependent cell-cell junctions. However, it was not the disruption of the E-cadherin regulatory complex but an excessive RhoA activation and disorganisation of actin fibres at the cell-cell junctions, induced by loss of CD151, that led to the enhancement of cell migration (Johnson et al, 2009). Through stabilisation of E-cadherin based cell-cell interactions, CD151 was suggested to counteract the metastatic progression of endometrial cancer (Voss et al, 2011). Activation of Rho/ROCK signalling axis triggered by loss of E-cadherin was recently demonstrated to be responsible for induction of anoikis resistance and invasive phenotype in a mouse model of human ILC (Schackmann et al, 2011). Interestingly, results of our own study have shown that in IDC cells, depletion of CD151 and $\alpha 3 \beta 1$ caused increase of active RhoA (Novitskaya et al, 2014). Taken together, these findings seem to suggest that although loss of E-cadherin is a prerequisite of the lobular phenotype, other factors, including, perhaps, the CD151- $\alpha 3 \beta 1$ partnership, also contribute to invasive behaviour of cancer cells.

The results of our study demonstrated that unlike IDC, lack of both CD151 and integrin $\alpha 3 \beta 1$ correlated with decreased survival of patients with lymph node-negative ILCs. Unlike IDC, ILC tumour cells are deprived of E-cadherin expression and the function and significance of the CD151/ $\alpha 3 \beta 1$ complex in biology of E-cadherinnegative cells are poorly characterised. However, it is conceivable that in this particular biological context, as in the settings described above, the CD151/ $\alpha 3 \beta 1$ complex is controlling cell-cell adhesion and loss of E-cadherin contributes but is not decisive in destabilisation of cellcell contacts and enhancement of cell migration.

The pathogenesis of IDC and ILC seems indeed to be governed by distinct mechanisms. Not only the high expression of CD151, but also the lymph node status, one of the most clinically important indicators of poor prognosis in IDC, was not correlated 
with survival of patients in our ILC study population. Instead, our results showed that the combined absence of CD151 and $\alpha 3 \beta 1$ was a negative prognostic factor in patients with no lymph node involvement. This unexpected finding gives a new insight into the biology of ILC and possible contribution of CD151 and $\alpha 3 \beta 1$ to disease progression. CD151 is highly expressed in endothelial cells and is thought to regulate pathologic angiogenesis. It has also been demonstrated that CD151 plays an important role in maintaining integrity of endothelial layer (Zhang et al, 2011). Our immunohistochemical analysis showed that the level of CD151 expression on endothelial cells was correlated with that seen on tumourassociated endothelium. Although the mechanisms underlying this 'phenotypic unity' remains unknown, it is possible that the compromised integrity of CD151-negative endothelium would facilitate intravasation of CD151-negative cells. Whatever the underlying mechanisms, the results of our study indicate that loss of CD151- $\alpha 3 \beta 1$ may serve as a potential prognostic marker of poor survival in a subgroup of patients deemed to carry a low risk of cancer-related death (ie, lymph node negative). This could have important clinical implications by helping to identify patients likely to benefit from adjuvant therapy.

In summary, the results of our comparative analysis of clinical significance of CD151/integrin $\alpha 3 \beta 1$ in ILC and IDC highlight considerable differences in biology between these two BCa types. Furthermore, the study suggests that evaluation of the level of CD151/ $\alpha 3 \beta 1$ expression might provide important information on behaviour of ILC tumours and identify patients with increased risk of distant metastases, commonly considered ineligible for routine adjuvant therapy.

\section{ACKNOWLEDGEMENTS}

This work was supported by the National Science Centre (Grant No. UMO- 2013/09/B/NZ4/02512 to HMR and UMO-2012/06/M/ $\mathrm{NZ3/00023} \mathrm{to} \mathrm{RS).}$

\section{CONFLICT OF INTEREST}

The authors declare no conflict of interest.

\section{REFERENCES}

Adachi M, Taki T, Huang C, Higashiyama M, Doi O, Tsuji T, Miyake M (1998) Reduced integrin alpha3 expression as a factor of poor prognosis of patients with adenocarcinoma of the lung. J Clin Oncol 16(3): 1060-1067.

Baldwin LA, Hoff JT, Lefringhouse J, Zhang M, Jia C, Liu Z, Erfani S, Jin H, Xu M, She QB, van Nagell JR, Wang C, Chen L, Plattner R, Kaetzel DM, Luo J, Lu M, West D, Liu C, Ueland FR, Drapkin R, Zhou BP, Yang XH (2014) CD151-alpha3beta1 integrin complexes suppress ovarian tumor growth by repressing slug-mediated EMT and canonical Wnt signaling. Oncotarget 5(23): 12203-12217.

Bertucci F, Orsetti B, Negre V, Finetti P, Rouge C, Ahomadegbe JC, Bibeau F, Mathieu MC, Treilleux I, Jacquemier J, Ursule L, Martinec A, Wang Q, Benard J, Puisieux A, Birnbaum D, Theillet C (2008) Lobular and ductal carcinomas of the breast have distinct genomic and expression profiles. Oncogene 27(40): 5359-5372.

Boucheix C, Rubinstein E (2001) Tetraspanins. Cell Mol Life Sci 58(9): 11891205.

Chattopadhyay N, Wang Z, Ashman LK, Brady-Kalnay SM, Kreidberg JA (2003) alpha3beta1 integrin-CD151, a component of the cadherin-catenin complex, regulates PTPmu expression and cell-cell adhesion. J Cell Biol 163(6): 1351-1362.

Chien CW, Lin SC, Lai YY, Lin BW, Lin SC, Lee JC, Tsai SJ (2008) Regulation of CD151 by hypoxia controls cell adhesion and metastasis in colorectal cancer. Clin Cancer Res 14(24): 8043-8051.
Chometon G, Zhang ZG, Rubinstein E, Boucheix C, Mauch C, Aumailley M (2006) Dissociation of the complex between CD151 and laminin-binding integrins permits migration of epithelial cells. Exp Cell Res 312(7): 983-995.

Deng X, Li Q, Hoff J, Novak M, Yang H, Jin H, Erfani SF, Sharma C, Zhou P, Rabinovitz I, Sonnenberg A, Yi Y, Zhou P, Stipp CS, Kaetzel DM, Hemler ME, Yang XH (2012) Integrin-associated CD151 drives ErbB2-evoked mammary tumor onset and metastasis. Neoplasia 14(8): 678-689.

Derksen PW, Liu X, Saridin F, van der Gulden H, Zevenhoven J, Evers B, van Beijnum JR, Griffioen AW, Vink J, Krimpenfort P, Peterse JL, Cardiff RD, Berns A, Jonkers J (2006) Somatic inactivation of E-cadherin and p53 in mice leads to metastatic lobular mammary carcinoma through induction of anoikis resistance and angiogenesis. Cancer Cell 10(5): 437-449.

Fukushima Y, Ohnishi T, Arita N, Hayakawa T, Sekiguchi K (1998) Integrin alpha3beta1-mediated interaction with laminin-5 stimulates adhesion, migration and invasion of malignant glioma cells. Int J Cancer 76(1): 63-72.

Gonzalez MA, Pinder SE, Wencyk PM, Bell JA, Elston CW, Nicholson RI, Robertson JF, Blamey RW, Ellis IO (1999) An immunohistochemical examination of the expression of E-cadherin, alpha- and beta/gammacatenins, and alpha2- and beta1-integrins in invasive breast cancer. J Pathol 187(5): 523-529.

Gonzalez-Angulo AM, Sahin A, Krishnamurthy S, Yang Y, Kau SW, Hortobagyi GN, Cristofanilli M (2006) Biologic markers in axillary nodenegative breast cancer: differential expression in invasive ductal carcinoma versus invasive lobular carcinoma. Clin Breast Cancer 7(5): 396-400.

Gui GP, Wells CA, Browne PD, Yeomans P, Jordan S, Puddefoot JR, Vinson GP, Carpenter R (1995) Integrin expression in primary breast cancer and its relation to axillary nodal status. Surgery 117(1): 102-108.

Gustafson-Wagner E, Stipp CS (2013) The CD9/CD81 tetraspanin complex and tetraspanin CD151 regulate alpha3beta1 integrin-dependent tumor cell behaviors by overlapping but distinct mechanisms. PLoS One 8(4): e61834.

Hemler ME (2005) Tetraspanin functions and associated microdomains. Nat Rev Mol Cell Biol 6(10): 801-811.

Hofmann M, Stoss O, Shi D, Buttner R, van d V, Kim W, Ochiai A, Ruschoff J, Henkel T (2008) Assessment of a HER2 scoring system for gastric cancer: results from a validation study. Histopathology 52(7): 797-805.

Johnson JL, Winterwood N, DeMali KA, Stipp CS (2009) Tetraspanin CD151 regulates RhoA activation and the dynamic stability of carcinoma cell-cell contacts. J Cell Sci 122(Pt 13): 2263-2273.

Kazarov AR, Yang X, Stipp CS, Sehgal B, Hemler ME (2002) An extracellular site on tetraspanin CD151 determines alpha 3 and alpha 6 integrindependent cellular morphology. J Cell Biol 158(7): 1299-1309.

Korkola JE, DeVries S, Fridlyand J, Hwang ES, Estep AL, Chen YY, Chew KL, Dairkee SH, Jensen RM, Waldman FM (2003) Differentiation of lobular versus ductal breast carcinomas by expression microarray analysis. Cancer Res 63(21): 7167-7175.

Kwon MJ, Park S, Choi JY, Oh E, Kim YJ, Park YH, Cho EY, Kwon MJ, Nam SJ, Im YH, Shin YK, Choi YL (2012) Clinical significance of CD151 overexpression in subtypes of invasive breast cancer. Br J Cancer 106(5): 923-930.

Lanzafame S, Emmanuele C, Torrisi A (1996) Correlation of alpha 2 beta 1 integrin expression with histological type and hormonal receptor status in breast carcinomas. Pathol Res Pract 192(10): 1031-1038.

Mirza AN, Mirza NQ, Vlastos G, Singletary SE (2002) Prognostic factors in node-negative breast cancer: a review of studies with sample size more than 200 and follow-up more than 5 years. Ann Surg 235(1): 10-26.

Novitskaya V, Romanska H, Kordek R, Potemski P, Kusinska R, Parsons M, Odintsova E, Berditchevski F (2014) Integrin alpha3beta1-CD151 complex regulates dimerization of ErbB2 via RhoA. Oncogene 33(21): 2779-2789.

Palmer TD, Martinez CH, Vasquez C, Hebron KE, Jones-Paris C, Arnold SA, Chan SM, Chalasani V, Gomez-Lemus JA, Williams AK, Chin JL, Giannico GA, Ketova T, Lewis JD, Zijlstra A (2014) Integrin-free tetraspanin CD151 can inhibit tumor cell motility upon clustering and is a clinical indicator of prostate cancer progression. Cancer Res 74(1): 173-187.

Romanska HM, Berditchevski F (2011) Tetraspanins in human epithelial malignancies. J Pathol 223(1): 4-14.

Sadej R, Grudowska A, Turczyk L, Kordek R, Romanska HM (2014) CD151 in cancer progression and metastasis: a complex scenario. Lab Invest 94(1): $41-51$.

Sadej R, Romanska H, Baldwin G, Gkirtzimanaki K, Novitskaya V, Filer AD, Krcova Z, Kusinska R, Ehrmann J, Buckley CD, Kordek R, Potemski P, Eliopoulos AG, Lalani E, Berditchevski F (2009) CD151 regulates 
tumorigenesis by modulating the communication between tumor cells and endothelium. Mol Cancer Res 7(6): 787-798.

Schackmann RC, van AM, Haarhuis JH, Vlug EJ, Halim VA, Roodhart JM, Vermaat JS, Voest EE, van der Groep P, van Diest PJ, Jonkers J, Derksen PW (2011) Cytosolic p120-catenin regulates growth of metastatic lobular carcinoma through Rock1-mediated anoikis resistance. J Clin Invest 121(8): 3176-3188.

Shigeta M, Sanzen N, Ozawa M, Gu J, Hasegawa H, Sekiguchi K (2003) CD151 regulates epithelial cell-cell adhesion through PKC- and Cdc42-dependent actin cytoskeletal reorganization. J Cell Biol 163(1): 165-176.

Sikora MJ, Cooper KL, Bahreini A, Luthra S, Wang G, Chandran UR, Davidson NE, Dabbs DJ, Welm AL, Oesterreich S (2014) Invasive lobular carcinoma cell lines are characterized by unique estrogen-mediated gene expression patterns and altered tamoxifen response. Cancer Res 74(5): 1463-1474.

Sikora MJ, Jankowitz RC, Dabbs DJ, Oesterreich S (2013) Invasive lobular carcinoma of the breast: patient response to systemic endocrine therapy and hormone response in model systems. Steroids 78(6): 568-575.

Tutt A, Wang A, Rowland C, Gillett C, Lau K, Chew K, Dai H, Kwok S, Ryder K, Shu H, Springall R, Cane P, McCallie B, Kam-Morgan L, Anderson S, Buerger H, Gray J, Bennington J, Esserman L, Hastie T, Broder S, Sninsky J, Brandt B, Waldman F (2008) Risk estimation of distant metastasis in nodenegative, estrogen receptor-positive breast cancer patients using an RT-PCR based prognostic expression signature. BMC Cancer 8: 339.

Voss MA, Gordon N, Maloney S, Ganesan R, Ludeman L, McCarthy K, Gornall R, Schaller G, Wei W, Berditchevski F, Sundar S (2011) Tetraspanin CD151 is a novel prognostic marker in poor outcome endometrial cancer. Br J Cancer 104(10): 1611-1618.
Wang Y, Klijn J, Zhang Y, Atkins D, Foekens J (2007) Gene expression profiles and prognostic markers for primary breast cancer. Methods Mol Biol 377: 131-138.

Weigelt B, Geyer FC, Natrajan R, Lopez-Garcia MA, Ahmad AS, Savage K, Kreike B, Reis-Filho JS (2010) The molecular underpinning of lobular histological growth pattern: a genome-wide transcriptomic analysis of invasive lobular carcinomas and grade- and molecular subtype-matched invasive ductal carcinomas of no special type. J Pathol 220(1): 45-57.

Weigelt B, Horlings HM, Kreike B, Hayes MM, Hauptmann M, Wessels LF, de JD, van de Vijver MJ, Van't Veer LJ, Peterse JL (2008) Refinement of breast cancer classification by molecular characterization of histological special types. J Pathol 216(2): 141-150.

Yang XH, Richardson AL, Torres-Arzayus MI, Zhou P, Sharma C, Kazarov AR, Andzelm MM, Strominger JL, Brown M, Hemler ME (2008) CD151 accelerates breast cancer by regulating alpha 6 integrin function, signaling, and molecular organization. Cancer Res 68(9): 3204-3213.

Zhang F, Michaelson JE, Moshiach S, Sachs N, Zhao W, Sun Y, Sonnenberg A, Lahti JM, Huang H, Zhang XA (2011) Tetraspanin CD151 maintains vascular stability by balancing the forces of cell adhesion and cytoskeletal tension. Blood 118(15): 4274-4284.

Zoller M (2009) Tetraspanins: push and pull in suppressing and promoting metastasis. Nat Rev Cancer 9(1): 40-55.

This work is published under the standard license to publish agreement. After 12 months the work will become freely available and the license terms will switch to a Creative Commons AttributionNonCommercial-Share Alike 4.0 Unported License. 